\title{
Congenital vascular anomalies: a case report
}

\begin{abstract}
Klippel-Trenaunay-weber syndrome is a rare congenital vascular anomaly usually presenting with port wine stains, excessive growth of bones and soft tissue, and varicose veins. This occurs most commonly in the legs, but it also may affect the arms, face, head, or internal organs. We report a term male neonate presented with port wine stain, big abdominal hemangioma, varicose veins and excessive growth of soft tissue of lower limbs consistent with Klippel-Trenaunay-Weber syndrome.
\end{abstract}

Keywords: Congenital vascular anomalies, Klippel-Trenaunay-weber syndrome
Volume 3 Issue 2 - 2015

\author{
Zahed Hussain Mir,' Juveria Wani, ${ }^{2}$ Tajamul \\ Shirazi ${ }^{1}$ \\ 'Department of Pediatrics, GMC Srinagar, India \\ ${ }^{2}$ Department of Gynae \& Obstetrics, SKIMS Medical College \\ Srinagar, India
}

\begin{abstract}
Correspondence: Zahed Hussain Mir, Senior Resident, Postgraduate Department of Pediatrics, GMC Srinagar, India, Tel
\end{abstract} 9596426868, Email zahidhussainmir2000@yahoo.com

Received: September 13,2015 | Published: November 04, 2015

\section{Introduction}

Klippel-Trenaunay-Weber syndrome is a rare congenital vascular anomaly characterized by a triad of port-wine stain, varicose veins, and bony and soft tissue hypertrophy involving an extremity. ${ }^{1}$ Mostly, it is idiopathic in origin; however, sometimes it may occur as an autosomal dominant trait. ${ }^{1,2}$ Klippel-Trenaunay-Weber Syndrome is a cutaneous vascular malformation affecting the development of blood vessels, soft tissues and bones. ${ }^{3}$ This is a non-heritable disorder which is present at birth and usually involves lower limb but may involve more than one limb and a portion of the trunk and face. ${ }^{4}$ Most people with Klippel-Trenaunay syndrome are born with a port wine stain. ${ }^{5}$ The port-wine stain usually covers part of one limb. ${ }^{6}$ The affected area may become lighter or darker with age. Klippel-Trenaunay syndrome is also associated with overgrowth of bones and soft tissue beginning in infancy. ${ }^{5} \mathrm{Klippel-Trenaunay} \mathrm{syndrome} \mathrm{is} \mathrm{estimated} \mathrm{to} \mathrm{affect} \mathrm{at} \mathrm{least}$ 1 in 100,000 people worldwide. ${ }^{7}$ It affects male and female equally, and not limited to any racial group. ${ }^{8}$ Klippel-Trenaunay- Weber syndrome is a rare congenital defect; that is why we are reporting this case. Recently International Society for the Study of Vascular Anomalies classified Vascular Anomalies and labelled Klippel-Trenaunay-Weber Syndrome as CM + VM +/- LM + limb overgrowth.

\section{Case report}

The index case, baby of ' $\mathrm{X}$ ' aged day 01 , a term male neonate of non-consanguineous parents, hailing from Rafiabad Baramullah, was admitted on April 25, 2015 in Post Graduate Department of Pediatrics GMC Srinagar with swelling of both the lower limbs, multiple macular, sharply circumscribed, pink colored, varied in size, vascular malformations, tortuous venous swelling in the medial aspect of right leg and a soft irregular movable swelling in the right thoracoabdominal region. The mother was 35 years of age; para 05 , gravida 05 . She was on regular antenatal checkup and the baby was born at term by normal vaginal delivery. On examination, the neonate had 4300 gm weight on admission, length $51 \mathrm{~cm}$, OFC $35 \mathrm{~cm}$; multiple port-wine stains were found predominantly on the lower limbs and the trunk, associated with non-pitting hypertrophied lower limbs and tortuous bluish colored varicose venous channels in medial aspect of right leg and near right axilla (Figure 1). There was a soft ill-defined movable swelling about $7 \times 5$ size $\mathrm{cm}$, not fixed with under lying structures or overlying smooth normal skin in thoracoabdominal area (Figure 2). There was no cardiac murmur and no bruit in other areas (e.g. gut, vascular channels), ophthalmologic examination was normal. On investigation, complete blood count including the thrombocyte count was normal, $\mathrm{x}$ ray babygram was also normal, ultrasonography of abdomen showed large cystic lesions in right upper quadrant of abdomen and around kidneys $(\mathrm{R}>1)$ and in retroperitoneum and that of head was normal and C-reactive protein was normal. Coagulogram was normal and echocardiography done did not show any cardiac malformation. The neonate was clinically diagnosed as a case of Klippel-Trenaunay-Weber syndrome. Verbal consent from parents was taken to report the case as a scientific paper.

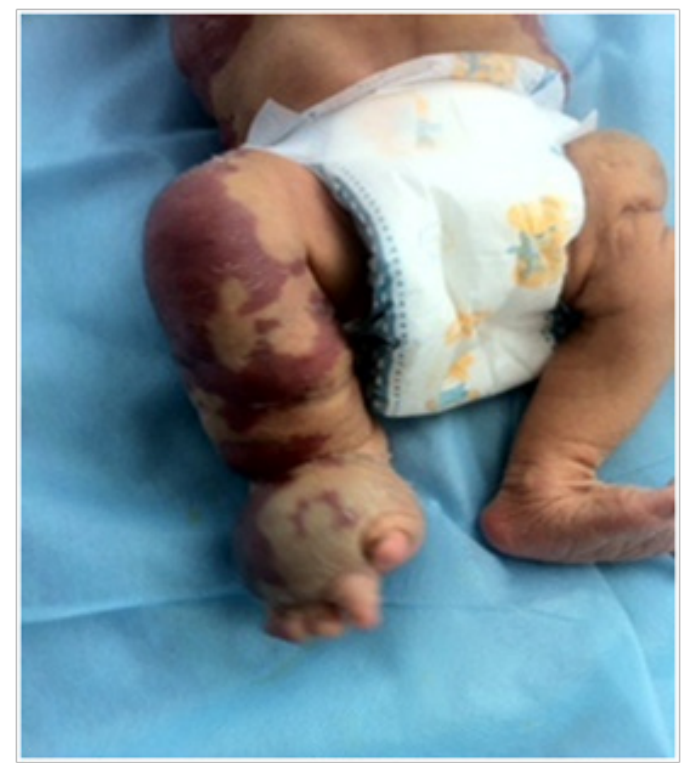

Figure I Non-pitting hypertrophied right lower limb.

\section{Discussion}

Port-wine stains may be present at birth. These vascular malformations consist of mature dilated dermal capillaries. 2 These lesions are macular, sharply circumscribed, pink to purple in color and tremendously variable in size.2 Port-wine stains can occur as a component of Klippel-Trenaunay-Weber Syndrome associated with soft tissue enlargement (i.e. hypertrophy of an extremity or a part of it). ${ }^{1}$ In this syndrome, the vascular malformation generally localized to the hypertrophied area; ${ }^{5}$ in this case, the both lower 
limbs are hypertrophied and stained with port-wine stains which was extending onto the trunk which is consistent with the other study. ${ }^{5,6}$ The deep venous system may be absent or hypoplastic. Venous blebs and/or vesicular lymphatic lesions may be present on their surface. Thick walled venous varicosities may be found along with vascular malformations; in this patient, varicose veins were in the medial aspect of right lower leg and near right axilla which is also consistent with the previous report. ${ }^{6}$

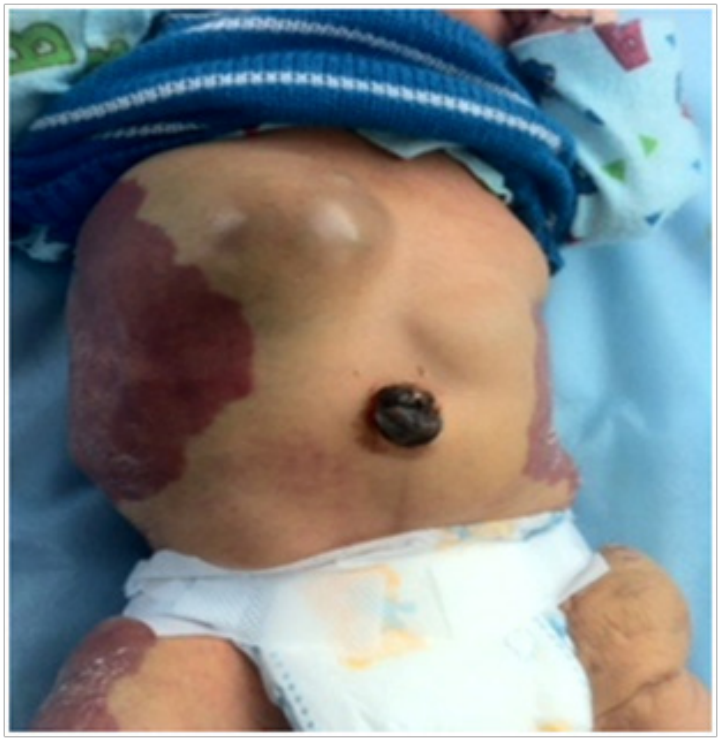

Figure 2 Soft ill-defined movable swelling in thoraco-abdominal area.

Sometimes there may be associated arterio-venous malformations; ${ }^{9}$ in this case, no such lesion was found. There may be some rare complications, e.g. thrombophlebities, dislocation of joints, gangrene of the affected extremities, heart failure, hematuria secondary to angiomatous involvement of urinary tract, rectal bleeding from lesions of gastrointestinal tract, pulmonary lesions and malformation of lymphatic vessels. ${ }^{10}$ No such complication was found in this case. Arteriogram, venogram and CT or MRI scans may delineate the extent of the anomaly but surgical correction or palliation is often difficult. ${ }^{11}$ Color echo, Doppler ultrasonography guided percutaneous sclerotherapy is of benefit when a venous component is the dominant vessel in the malformation. ${ }^{7}$ The most effective treatment for portwine stains is the pulsed dye laser (PDL). After such treatment, the texture and pigmentation of the skin are usually normal without scarring. Supportive care includes compression bandages for varicosities; surgical treatment may help. Leg-length discrepancy should be treated with orthotic devices to prevent the development of spinal deformities. Corrective bone surgery may eventually be needed to treat significant leg-length discrepancy. ${ }^{6}$ Maffuci syndrome is a close differential diagnosis of Klippel-TrenaunayWeber syndrome; ${ }^{7}$ it consists of numerous vascular and occasionally lymphatic malformations with nodular enchondromas in metaphyseal or diaphyseal part of long bones. ${ }^{7}$ Vascular lesions are typically soft, compressible, asymptomatic blue-to-purple subcutaneous masses that grow in proportion to a child's growth and stabilize by adult life; ${ }^{6}$ no such lesions were found in this particular case. Besides, mucous membranes or viscerae may also be involved and onset occurs during childhood; 7 here, the onset is at birth with the presentation of Portwine stains, venous varicosities and soft tissue hypertrophy of lower limbs, which is consistent with Klippel-Trenaunay-Weber syndrome. Milroy syndrome may also come into the differential diagnosis if surface vascular lesion i.e. port-wine stain is minimal, however, port- wine stains were widely distributed in this case which was contrary to Milroy syndrome. ${ }^{1}$ This case was clinically diagnosed as a case of Klippel-Trenaunay-Weber syndrome and was given supportive treatment.

\section{Conclusion}

Klippel-Trenaunay-Weber syndrome is a very rare developmental vascular anomaly consisting of port-wine stain, excessive growth of bones and soft tissue and varicose veins; diagnosis is mainly clinical, however, sometimes investigations e.g. arteriogram, venogram and $\mathrm{CT}$ or MRI may help to determine the extent of anomaly. Treatment usually requires counseling, supportive treatment, laser therapy, compression bandages for varicosee veins; Doppler ultrasonography guided percutaneous scleotherapy and corrective surgery in selective cases. Corrective bone surgery may eventually be needed to treat significant leg-length discrepancy.

\section{Acknowledgments}

None.

\section{Conflicts of interest}

The authors declare there is no conflict of interests.

\section{Funding}

None.

\section{References}

1. Cohen MM. Klippel-Trenaunay syndrome. Am J Med Genet. 2004;93(3):171-175.

2. Jacob AG, Driscoll DJ, Shaughnessy WJ, et al. Klippel- Trenaunay syndrome:spectrum and management. Mayo Clin Proc 1998;73(1):2836.

3. Mendiratta V, Koranne RV, Sardana K. Klippel trenaunay Parkes Weber syndrome. Indian Journal of Dermatology, Venereology and Leprology. 2004;70(2):119-122.

4. Hofer T, Frank J, Itin PH. Klippel-Trenaunay syndrome in a monozygotic male twin:supportive evidence for the concept of paradominant inheritance. Eur J Dermatol. 2005;15(5):341-343.

5. Kihiczak GG, Meine JG, Schwartz RA, et al. Klippel-Trenaunay syndrome:a multisystem disorder possibly resulting from a pathogenic gene for vascular and tissue overgrowth. Int J Dermatol. 2006;45(8):883890 .

6. Funayama E, Sasaki S, Oyama A, et al. How do the type and location of a vascular malformation influence growth in Klippel-Trénaunay syndrome?. Plast Reconstr Surg Jan. 2011;127(1):340-346.

7. Barker KT, Foulkes WD, Schwartz CE, et al. Is the E133K allele of VG5Q associated with Klippel- Trenaunay and other overgrowth syndromes. J Med Genet. 2006;43(7):613-614.

8. Darmstadt GL, Sidbury R. The Skin. In: Behrman RE, Kliegman RM, editors. Nelson Textbook of Pediatrics. 17th edn. Saunders, Philadelphia, USA; 2004:2167-2171.

9. Burrows NP. Disorders of the Skin. In: McIntosh N, Helms et al. editors. Forfar \& Arneil"s Textbook of Pediatrics. 6th edn. London:Churchill Livingstone, USA, 1678; 1998.

10. Rogers M. Neonatal Dermatology. In:Rennie JM (Ed.), Roberton”s Textbook of Neonatology. 4th edn. London: Elsevier Churchill Livingstone USA; 2005. 830 p.

11. James DW, Berger T, Elston D. Andrews" diseases of the skin: clinical dermatology. 10th edn. Philadelphia: Saunders, USA; 2005. 585 p. 